\title{
LA JUSTICIA RESTAURATIVA EN LA EJECUCIÓN PENAL: LA CAPACIDAD EMPÁTICA DE LAS PERSONAS PRESAS ${ }^{1}$
}

\author{
Julián Carlos Ríos Martín \\ Profesor Derecho Penal y Justicia Restaurativa. Universidad Comillas (ICADE). \\ Mediador en procesos restaurativos. \\ Title: Restorative Justice during the serving of the sentence: \\ The inmates' capacity for empathy.
}

Resumen: Este artículo busca incorporar la voz de las personas condenadas, internas en centros penitenciarios. Queremos conocer su capacidad para asumir la responsabilidad por los hechos delictivos cometidos. También, para enfrentarse a un dialogo restaurativo con la víctima.

Palabras Clave: Justicia Restaurativa; Sistema penal; Cárceles; Reparación; Reeducación.

Abstract: This article aims at giving voice to people convicted that are serving their sentence in prison. The objective is to know their capacity to take responsibility for the offences they have committed, as well as to undertake a restorative dialogue with the victim.

Keywords: Restorative Justice; Criminal Justice System; Prisons; Reparation; Reintegration.

Sumario: 1. Introducción. - 2. La necesidad de una mirada crítica al sistema penal. - 3. Ampliando perspectivas: La Justicia Restaurativa. - 4. La voz de los presos: ¿asumen su responsabilidad? - 5. Los presos y la empatía. - 5.1. Sentimientos de malestar o pesar por el delito cometido y cercanía a la víctima. - 5.2. Ausencia de sentimientos, indiferencia por el delito cometido y hacia la víctima, necesidad de olvidar o simplemente falta de opinión. - 5.3. Mecanismos exculpatorios o de derivación de responsabilidad: ¡la víctima soy yo!, exculpaciones genéricas o proclamas de inocencia (reales o ficticias), exculpaciones por causa de la droga o por el mal funcionamiento del sistema penal, incluso haciendo responsable a la

1 El presente trabajo se enmarca dentro del Proyecto I+D+I con el título «Exclusión social y sistema penal y penitenciario: análisis y propuestas acerca de tres realidades (inmigración y refugio, enfermedad mental y prisión). pid2019-105778rb-i00. Departamento Derecho penal de la Universidad Complutense de Madrid. 
propia víctima; o simplemente lo sienten por las consecuencias sobre su propia familia. 6. La empatía de los presos enfrentados cara a cara con la víctima. - 6.1. Sentimientos de pesar o arrepentimiento por el delito cometido y cercanía a la víctima. - 6.2. Ausencia de sentimientos, indiferencia por el delito cometido y hacia la víctima, necesidad de olvidar, consideración de falta de víctima o simplemente carencia de opinión. -7 . Conclusiones. -8 . Bibliografía. - 9. Prensa.

\section{Introducción}

Desde nuestra experiencia, la incorporación de encuentros o diálogos restaurativos en la fase de ejecución penal satisface necesidades profundas de la víctima en orden a alcanzar cierta paz interior y abandonar el odio que, según dicen algunas, no les permite vivir ${ }^{2}$. A su vez, facilita al victimario la posibilidad de asumir su responsabilidad y asegurar, en una alta probabilidad, garantías de que el delito no se vuelve a cometer, coadyuvando, de esta manera, a la eficacia de los fines que el Derecho penal tiene asignados. En este trabajo analizaremos, desde una investigación desarrollada desde la Universidad Comillas, la voz de 1500 presos en torno a su posibilidad y capacidad de ponerse en el lugar de la víctima.

Y, previo a ello, consideramos imprescindible una mirada crítica al sistema penal. La condescendencia acrítica con su funcionamiento institucional restaría humanidad a la intervención punitiva. Ello incrementaría un sufrimiento añadido. Dejaría en una mera anécdota los beneficios de la Justicia restaurativa.

\section{La necesidad de una mirada crítica al sistema penal}

Hablar de Derecho penal es hablar de violencia. Violentos son los comportamientos delictivos, a veces terribles e irreparables. Violenta, a veces también irreparable, es la gestión que el Estado hace del comportamiento delictivo ${ }^{3}$. En ambas direcciones están implicados los seres humanos, y también las instituciones a las que sirven. Es noble el objetivo de intentar atemperar el sufrimiento. Estoy convencido de que, a este fin, con mayor o menor eficacia, intentan servir la mayoría de las personas y profesionales que sufren o trabajan en la administración de justicia penal.

2 Desde 1974, a raíz del experimento «Kitchener», ha existido un creciente interés por establecer programas de justicia restaurativa como complemento o alternativa a los sistemas de justicia penal de estilo occidental: M. Rossner, Just emotions. Rituals of restorative justice, Oxford, Oxford University Press, 2013.

3 Un ejemplo: cada año mueren en la cárcel cumpliendo sentencias condenatorias, aproximadamente, doscientas personas. Véanse los informes anuales en Secretaría General de Instituciones Penitenciarias, Informe sobre mortalidad en instituciones penitenciarias, Ministerio del Interior. 
La complejidad de la política criminal, debido a la multifactorialidad de las causas, enfoques, posiciones ideológicas y modelos de sociedad, me lleva a hablar con humildad. Dudo de la neutralidad de la percepción de los fenómenos sociales; también de la mía. Por esto quiero ser sincero y señalar que las reflexiones que siguen están realizadas desde mi experiencia profesional y personal. Desde hace 28 años me dedico al Derecho penal; 15 de ellos ejerciendo como abogado defensor de personas en situación de precariedad y exclusión social que han delinquido; los 28 años asesorando a personas privadas de libertad en las cárceles, al mismo tiempo que he acogido a personas en mi casa para apoyar procesos de reinserción social; los siete últimos trabajando desde el Consejo Asesor del Mecanismo Nacional de Prevención de la Tortura del Defensor del Pueblo; y otros tantos trabajando como profesor de Derecho penal en la universidad Comillas y desarrollando varias investigaciones dedicadas a conocer las condiciones de vida en los centros penitenciarios. También en los últimos años me he dedicado a trabajar en espacios de mediación penal y de encuentros restaurativos entre víctimas e infractores. Obviamente, mi percepción es selectiva, no lo puedo negar. Pongo en el centro de la reflexión al ser humano y su sufrimiento.

Junto a la innegable necesidad social del sistema penal en las tareas de prevención delictiva y justicia, aparecen, en su definición y aplicación, disfunciones que generan graves consecuencias en los seres humanos y ponen en duda su legitimidad, a pesar de que esta venga sostenida por los objetivos preventivos y la garantía del principio de proporcionalidad ${ }^{4}$. El conocimiento de las mismas, más allá de la realidad más o menos perfecta que los operadores jurídicos creen conocer en función de su trabajo, universo emocional o ideológico, es fundamental para valorar la legitimidad de determinadas políticas criminales o instituciones punitivas ${ }^{5}$.

Proponemos un cambio de mirada: de la autocomplacencia a la crítica; de una mirada genérica basada en el presupuesto del correcto funcionamiento de cada institución, a la agudeza de atreverse, osadamente,

${ }^{4}$ La pena es legítima cuando, sin rebasar los límites que derivan del principio de proporcionalidad, resulta eficaz desde el punto de vista preventivo; más concretamente, cuando proporciona la máxima eficacia preventiva, atendiendo tanto a su eficacia preventiva general, como a su eficacia preventiva especial, y a los distintos cauces a través de los cuales el recurso a la pena puede producir un efecto preventivo (función preventiva limitada por el principio de proporcionalidad): S. CARDENAL MONTRAVETA, « ¿Eficacia preventiva general intimidatoria de la pena? Consecuencias para la decisión sobre la suspensión de su ejecución», Revista Electrónica de Ciencia Penal y Criminología (RECPC), n 17-18, 2015; S. Mir Puig, Derecho Penal. Parte General, Valencia, Tirant Lo Blanch, 2015.

${ }^{5}$ Las instituciones de la administración — policía, jueces, fiscales, abogados y administración penitenciaria- que buscan la justicia y la verdad, con la estricta aplicación de la legalidad y la protección formalista de los derechos fundamentales pueden generar espacios y situaciones de desigualdad, impunidad, abuso y maltrato institucional. Todo ello genera graves consecuencias en la salud física y mental de quienes acuden al sistema penal, bien como acusados, bien como víctimas. 
a observar desde otro lado: el de los lugares silenciados y oscurecidos de las instituciones punitivas o de las políticas criminales seleccionadas; y, como no, desde las voces mudas, o enmudecidas, de quienes son protagonistas del proceso ${ }^{6}$. Ello es esencial si se quiere garantizar la convivencia social, el respeto a los Derechos Humanos, la dignidad y la legitimidad del sistema penal ${ }^{7}$. Y, para que quienes investigan en búsqueda de la verdad, acusan y juzgan puedan decir que su trabajo en favor de la colectividad y, por tanto, en pro de cada una de las personas que lo conforman, no haga sufrir a nadie ni un ápice más de lo estrictamente necesario ${ }^{8}$. La tarea es compleja, sin duda, pues la búsqueda de la eficacia lleva, en ocasiones, a violentar derechos individuales.

Creo que la compasión, sentimiento poco cultivado en los tribunales, cárceles y comisarías, no se contrapone a la aplicación de la ley, sino que favorece, la consecución de la justicia: la que toma en cuenta las necesidades reales, vitales y profundas de las personas (víctimas y victimarios) y que pueden no coincidir con las que el proceso penal busca o cree satisfacer. La toma de conciencia en búsqueda de la verdad, la reparación y la prevención del delito, exige una mirada donde esté implicado el ser humano en toda su complejidad y no sólo su apariencia ${ }^{9}$.

6 Para una mayor información en estos aspectos es bueno leer los siguientes libros: J. Valverde Molina, La cárcel y sus consecuencias, Madrid, Edit. Popular, 2004; Ríos Martín, J.C. y Cabrera Cabrera, P.J., Mil voces presas, Madrid, Universidad Pontifica Comillas, 1999 y Los Mismos, Mirando el abismo: el régimen cerrado, Madrid, Universidad Pontifica Comillas, 2003.

7 «La definición de las conductas humanas que puedan ser calificadas como delitos, así como la determinación de las penas, pertenece al Estado. Varios motivos sostienen esta opinión, pero entre ellos, uno es fundamental: el poder que se otorga al Estado para establecer leyes penales y la regulación de las instituciones de la administración de justicia tiene como fundamento evitar la venganza privada y sustituirla por un sistema racional de castigos sometidos a unos límites establecidos en la Constitución: los Derechos Humanos. Esta racionalidad puede, no solo pedirse, sino exigirse a los políticos. No obstante, es un deber que olvidan fácilmente, porque les resulta más cómodo traducir en normas el clamor de la calle, sea justo o injusto, que intentar que la opinión pública discurra dentro del marco de la racionalidad»: T. VIVES ANTóN, «La injerencia, el error y el derecho», Diario El País, 1 de abril de 2010.

${ }^{8}$ Los efectos socio personales pretendidos con la conminación, imposición y ejecución de las penas, por muy necesarios que parezcan, en ninguna circunstancia deben superar ciertos confines. Uno de ellos es el de la humanidad de las sanciones, que viene a expresar que algunas de ellas, o determinadas formas de ejecución, son incompatibles con la dignidad de la persona humana, por lo que no pueden imponerse, cualquiera que sea la entidad lesiva del comportamiento o la intensidad de la responsabilidad personal. Otro de los confines a no superar es el de la proporcionalidad, en virtud del cual la pena debe ajustarse en su gravedad a la del comportamiento delictivo al que se conecta, debiendo mantener una correspondencia sustancial con él: J.L. DIEZ RIPOLLÉs, «El nuevo modelo penal de la seguridad ciudadana», RECPC, $\mathrm{n}^{\circ}$ 06-03, 2004.

9 El magistrado Saez Valcarcel lo define perfectamente: «el juez debería ser un espectador emotivo capaz de identificar en el proceso el sufrimiento ajeno para tutelar los derechos e intereses legítimos de los más débiles, dentro de lo que el ordenamiento jurídico le permite, su poder de disposición, que en muchas ocasiones no es pequeño, razonando 
Y, desde ese lugar, poder dar voz a quienes están presos. Escucharlos en sus sentimientos, hacia la toma de conciencia y la responsabilización por los delitos cometidos ${ }^{10}$. Y, paralelamente, saber que ello tiene una incidencia directa en la reparación a la víctima. A ello se dedica este trabajo.

\section{Ampliando perspectivas: La Justicia restaurativa}

Desde el año 2005 me he dedicado a trabajar en equipos de mediación penal intrajudicial y en encuentros restaurativos entre víctimas e infractores de delitos violentos: personas que abandonaron la organización terrorista ETA y víctimas del terrorismo ${ }^{11}$; con familiares víctimas del GAL y de quienes participaron en su organización; quien vendió los explosivos del terrible atentado del 11.m y una persona gravemente herida que iba en el tren. Y, con todo, mi gran aprendizaje no ha sido sólo una amplia y rigurosa formación técnica, ni siquiera la experiencia objetiva vivida, sino la interpretación e integración seria y profunda del todo ello en mi proceso vital desde espacios terapéuticos y de crecimiento personal.

A lo largo de esta dilatada experiencia restaurativa, he constatado que cuando una persona comete un delito contra otra, ambas quedan unidas. Necesitan tomar distancia, separarse, liberarse, pero no es posible. Es como si una cuerda elástica e invisible, pero amordazada emocionalmente en el cuerpo, les sujetase en un nivel inconsciente. No pueden huir. Víctimas y perpetradores caminan juntos. Buscan distanciarse pero, desde ella, se agreden. La víctima busca venganza como compensación de la injusticia sufrida a través de la petición de elevadas penas dentro de los márgenes que para cada delito marca el código penal: pide dolor para su agresor, proporcional al suyo. Por otra, el perpetrador — si realmente ha cometido el delito- continúa agrediendo cada vez que oculta la verdad, escondiéndose en su autojustificación, en la irresponsabilidad ${ }^{12}$.

siempre desde el derecho» (...) «frente al modelo de juez técnico que se escuda detrás de conceptos abstractos»: R. SAEZ VAlCARCEL, Entrevista. Revista Galde. Otoño 2016.

10 Como añade Gustafson, los ofensores empiezan a curar su trauma a través de la aceptación de sus acciones. Los ofensores necesitan seguridad y relaciones con otros para asumir la responsabilidad del daño causado, y para reconocer daños que ellos mismos han podido sufrir: D. L. GUSTAFSON, «Exploring treatment and trauma recovery implications of facilitating victim-offender encounters in crimes of severe violence: lessons from the Canadian experience», en E. Elliott y R.M. Gordon (eds.), New Directions in Restorative Justice: Issues, Practice, Evaluation, Cullompton, UK, Willan Publishing, pp. 193-227.

11 E. Pascual Rodriguez, (coord.), Los ojos del otro, Santander, Salterrae, 2013.

12 J.C. Ríos Martin, Biografía de la reconciliación. Palabras y silencios parar sanar la memoria, $2^{\mathrm{a}}$ ed., Granada, Comares, 2020. 
En este escenario aparece la intervención de la justicia penal como medio necesario para equilibrar la injusticia sufrida. Este es el primer paso. Es una respuesta social imperfecta, en ocasiones rabiosamente impersonal, insatisfactoria para las necesidades vitales, y desproporcionada para el agresor, pero necesaria en este nivel del que hablamos. Sin ella, la víctima difícilmente puede iniciar el tránsito hacia la liberación. Quedará atada por años a la búsqueda de la verdad y de la justicia formal. No es posible hacer un duelo sin este primer requisito.

Con el paso de los años, ambos protagonistas pueden acabar agotados, de sufrimiento. He conocido víctimas que, cansadas emocionalmente, necesitan encontrar serenidad para no enfermar y poder vivir. También he convivido con agresores que, en su experiencia de dolor, ya no se pueden esconder de sí mismos, ni de sus actos, ni permanecer atados a las lealtades ideológicas o creencias que justificaron su acto criminal. Ambos necesitan elaborar algo más grande: una humanidad compartida que les permita su efectiva separación y una re-significación de los acontecimientos.

Este es el segundo paso: la búsqueda de la paz para sanar el pasado y poder vivir el presente. La necesidad de liberación es de quien sufrió el delito; la fuerza y el impulso para ello tiene que partir del perpetrador y, cuando ello ocurre, se convierte en instrumento para la paz. Conozco víctimas en las que el odio y la ira, aunque fueron emocionalmente adaptativos en los tiempos cercanos al delito, les acaban ahogando. $\mathrm{He}$ conocido agresores que buscan asumir su responsabilidad, expresarla y encontrar una explicación a su violencia, a pesar de que la respuesta del Estado penal, tan desproporcionada, les dificulte el proceso. Y llegan a este puerto de forma consciente o inconsciente. Las experiencias de su vida: muertes de familiares, sufrimientos de amigos, el paso por experiencias vitales, nacimiento de hijos o la irracionalidad del daño, pueden provocar un movimiento tendente a abandonar el sistema de creencias justificadoras que les permite esconderse. Quedar a la intemperie del sistema de ideas y creencias, muchas veces heredadas y otras aprendidas en los primeros años, supone la necesidad de afrontar el vacío y la soledad. Asumir la culpabilidad de quebrantar la lealtad de un sistema, sostener la mala conciencia por ello, es una oportunidad para ponerse al servicio de la víctima. Aquí aparece la compasión; este sentimiento que nos humaniza y deviene no de sentirse «bueno» frente al otro «malo», sino de poder llegar a explicitar que el dolor del otro es mi dolor, no un resultado de la causa de mis lealtades a un grupo, clase social o idea. La otra cara de la moneda: llegar a intuir que la trasgresión del otro, es como la mía, o la de mis antepasados: entre nosotros no hay tanta distancia: mataron o agredieron ellos, quizás agredieron o mataron los míos —antepasados-. Ahí, mirándonos, reconociéndonos, podemos abrazarnos.

En este escenario aparece la Justicia restaurativa con sus instrumentos. Completan la solución imperfecta e inhumana que ha dado el sistema 
penal —aunque necesaria-. Víctima y perpetrador necesitan abandonar sus personajes. Para ello, tienen que verse, mirarse, escucharse, reconocer la humanidad quebrada del otro, para que pueda ser reconstruida. Quien sufrió el delito necesita poder narrar el sufrimiento, que ha de ser profunda y respetuosamente escuchado. De su mano necesita conocer la verdad, la más auténtica, la que se encuentra escondida en el perpetrador. Con estos pasos, es vista y reconocida en su humanidad por quien la quebró; el agresor, desde su escucha y desde su honestidad, lo puede facilitar. Un tercer movimiento ha de partir de quién fue víctima: ver la humanidad del agresor. Este ha de ser igualmente visto. Para ello, es preguntado por su historia de dolor. Ahí, en este lugar, ambos pueden encontrarse y separarse. Uno, para alcanzar la serenidad integrando esta experiencia en su itinerario vital, el otro, tomando conciencia de su responsabilidad y quizás comprendiendo el origen transgeneracional, si se asoma a ello, de ese terrible e imparable carro al que un día se subió ${ }^{13}$. Los destinos se separan. Un día, en un terrible momento, misteriosamente, se unieron.

La articulación de estos procesos restaurativos la hacemos bajo el paradigma de la Justicia restaurativa ${ }^{14}$. Esta supone una concepción fuerte, abierta y positiva del ser humano, de la sociedad y de «otra» idea de Justicia de contornos todavía no perfectamente definidos, pero claramente perfilables por oposición a la justicia punitiva-adversarial, de base retributiva o preventiva, y que van siendo traducidos en documentos y prácticas de los organismos especializados de la Organización de Naciones Unidas ${ }^{15}$.

No supone una enmienda al sistema punitivo. Considera que los conflictos son inevitables en la vida de las personas. Somos capaces de actos sublimes que nos dignifican a todos (incluso a los más timoratos) y de las mayores aberraciones. Conscientes de las patologías del ser humano y del sistema penal, así como de la necesidad de que este sea el soporte

13 Recientemente, la revista Science, en su número de abril de 2017, publicó un artículo con los resultados de una investigación llevada a cabo por científicos del Centro de Regulación Genómica (CRG) en Barcelona, el Instituto de Investigación contra la Leucemia Josep Carreras y el Instituto de Investigación Germans Trias y Pujol, en el que afirmaban haber descubierto que el impacto de los cambios ambientales se puede transmitir en los genes de hasta 14 generaciones. El «recuerdo» de una situación estresante a la que habían sido sometidos determinados animales se mantenía en sus transgenes «durante, al menos, catorce generaciones»: A. KLOSIN, ET AL., «Transgenerational transmission of environmental information in C. elegans» Science, 21 abril 2017.

14 A. Olalde Altarejos, 40 ideas para la práctica de la justicia restaurativa en la jurisdicción penal, Madrid, Dykinson, 2017.

15 Véanse, dentro del Consejo de Europa, la Recomendación N. ${ }^{\circ}$ R. (99) 19 del Comité de Ministros sobre la mediación en asuntos penales; la Resolución Ministerial N. ${ }^{\circ} 2$ sobre la misión social del sistema de justicia penal (2005); así como la Recomendación N. ${ }^{\circ} \mathrm{R}$. (2006) 8 sobre la asistencia a las víctimas. Dentro de Naciones Unidas cabe mencionar los Principios básicos sobre la utilización de los programas de la justicia restaurativa en asuntos penales (2002) y el Manual de Programas de Justicia Restaurativa (2006). Así mismo, se puede ver la edición de 2020 del Manual de las Naciones Unidas; Recomendación del Consejo de Europa de 2018, Directiva de 2012). 
último de valores sociales y bienes jurídicos protegibles (en tanto amparan necesidades fundamentales) ${ }^{16}$, la Justicia restaurativa defiende una dimensión de la dignidad humana no siempre suficientemente destacada: su carácter perfectible, su posibilidad de cambio, su potencial enorme de posibilidades frente a toda predeterminación, incrementando la capacidad de comprensión, de toma de conciencia de los límites y los esquemas mentales construidos o heredados ${ }^{17}$.

Naturalmente no es la panacea universal — tampoco la Justicia basada en la pena como casi única respuesta al delito- pero sí algo más que una novedosa «tercera vía» o un mero complemento de la Justicia vigente ${ }^{18}$.

\section{La voz de los presos: ¿asumen su responsabilidad?}

Desde estos presupuestos vinculados a la Justicia restaurativa, el área de Derecho Penal y el Departamento de Sociología de la Universidad Pontificia Comillas iniciamos un trabajo de investigación para conocer el alcance que habían tenido en la ejecución de la pena de prisión las reformas penales que adquirieron vigencia en el año 2003. Entre los diversos métodos de investigación utilizados — análisis de datos estadísticos, visitas a centros penitenciarios, entrevistas con expertos, etc.- uno, del máximo interés, consistió en la elaboración de un cuestionario que se distribuyó entre las personas presas en las cárceles españolas ${ }^{19}$. Fijamos la muestra para su eficaz representatividad desde criterios científicos y

16 Véase el comunitarismo como fuente ideológica destacable de la justicia restaurativa en P. Francés LecumberRI, y E. SANTOS Itoiz, "La mediación penal, ¿uu modelo de justicia en el sistema de justicia penal?», Nuevo foro penal, vol. 6, n. 75, 2010, pp. 53-93.

17 Véase las aportaciones filosóficas en justicia restaurativa en T. GAVRIELIDES, Y V. ARTINOPOUlou, Reconstructing restorative justice philosophy, Farnham, Ashgate, 2013.

18 M. Martínez Escamilla, «Justicia restaurativa, mediación y sistema penal: diferentes estrategias, ¿los mismos objetivos?», en VVAA, Estudios Penales en homenaje a Enrique Gimbernat, tomo I, Madrid, Edisofer, 2008. Una amplia y profunda visión sobre justicia restaurativa y sus métodos puede verse en los diversos trabajos de Gemma Varona: G. VARONA MARTínez, La mediación reparadora como estrategia de control social, Granada, Comares, 1998.Véanse también los trabajos del European Forum sobre el método de las conferencias, tema específico del Congreso celebrado en Bilbao en junio de 2010. Esencial leer las obras del profesor Josep Tamarit Sumalla.

19 En esta investigación se trabajó con los datos obtenidos en una encuesta que fue respondida por las personas encarceladas. Quienes trabajamos en este proyecto considerábamos esencial conocer la versión de los presos, al ser esta la más desconocida y difícil de conseguir. Además, añadimos el punto de vista de jueces de vigilancia penitenciaria, abogados, directores, responsables de tratamiento, psicólogos, juristas criminólogos y trabajadores sociales. Esta pluralidad de enfoques metodológicos solo pudo ser llevada a la práctica sobre el terreno gracias al apoyo de la Secretaria General de Instituciones Penitenciarias (SGIP), al frente de la que, entonces, se hallaba Mercedes Gallizo. Nos autorizó a visitar varias prisiones elegidas por nosotros: Puerto I, Aranjuez, Ocaña I, Villabona, Topas, Brieva, Alcalá-Meco, Soto del Real, El Dueso, Córdoba y Badajoz. 
remitimos las preguntas a cinco mil personas; obtuvimos respuesta de un número más que significativo considerando el volumen de población penitenciaria: $1700^{20}$.

En el cuestionario, además de preguntar sobre cuestiones penitenciarias, quisimos conocer los sentimientos de las personas respecto del delito cometido y la víctima. El objetivo que hemos buscado ha sido dar voz a los presos, permitirles que afloraran sus emociones contenidas que en otro caso correrían el riesgo de «morir» encapsuladas en la celda ${ }^{21}$. Nos guió la intuición de que ese secreto mundo emocional podría dar pautas inéditas al legislador, a los operadores jurídicos y a los ciudadanos en general $^{22}$. Esta parte no la publicamos en la investigación final; y es, ahora, en este artículo, cuando sale a la luz.

Nos centramos en dos preguntas para que las contestasen las personas encarceladas previa advertencia de la total confidencialidad de los cuestionarios. La primera estaba basada en los sentimientos que tenía respecto de la víctima del delito; contestaron 836 personas. La segunda invitaba a situarse virtualmente frente a la víctima y plantearse qué les dirían; contestaron 584 personas.

En las líneas que siguen haremos una descripción de cada apartado y, en ellos, describiremos y analizaremos las emociones expresadas. El estudio nos ha brindado la oportunidad de visibilizar emociones nunca expresadas. Frente al habitual desconocimiento, que limita a la persona condenada a un ser de maldad intrínseca, nos permitimos facilitar otro escenario donde pudiera expresarse libremente toda la gama de emociones vividas por los infractores y que posibilitan una visión más completa de ellos y de sus circunstancias.

En este estudio no nos hemos querido quedar en las respuestas cuantitativas fáciles de baremar (edad de comisión del delito, años de condena, etc.). Tampoco en variables cualitativas esperables (opiniones sobre las condiciones de prisionización, oportunidades de reinserción, etc.). Hemos pretendido ir más allá y bucear en el fondo de los sentimientos de las personas encarceladas. Lo hemos hecho tratando de determinar en concreto la capacidad del infractor para ponerse en el lugar de su víctima: la empatía. A raíz de ello, las personas privadas de libertad nos han volcado una torrentera de sentimientos auténticos.

${ }^{20}$ En otros países sí existen muchos estudios. En concreto, en relación con la justicia restaurativa, véase el resultado de un proyecto en prisión en el que participó España: I. BrenNan, y E. KLAASEN (dirs.), Building Bridges Restorative Dialogues between Victims and Offenders A Guide to Establishing and Running the Building Bridges Program, 2015.

${ }^{21}$ Los testimonios que se exponen a continuación se mantienen tal y como los recibimos. Las faltas de ortografía no se han corregido para mantener la originalidad.

${ }^{22}$ M. Gallego Díaz, P. Cabrera Cabrera, J. C. Rios Martín y J.L. Segovia Bernabé, Andar $1 \mathrm{~km}$ en línea recta: La cárcel del siglo XXI que vive el preso, Madrid, Universidad Pontificia Comillas, 2012. 
En efecto, la capacidad de empatía, de ponerse en la piel del otro, constituye una dimensión básica para las relaciones interpersonales y comunitarias y para una convivencia pacífica basada en el principio de solidaridad. Podría pensarse (y así se hace con frecuencia) que estos sentimientos son ajenos por completo a las personas que han causado un daño personal y social; más aún si están entre rejas. Pues bien, el estudio que presentamos muestra justamente lo contrario.

En verdad, los presos sienten y lloran. (No ocultaremos la terrible desazón que nos provoca la constatación de que en algunos pocos casos se trata de lágrimas inocentes derivadas de error judicial). Y su padecimiento tiene que ver, en ocasiones, con la incapacidad de explicarse, de dar cuenta sosegada de lo sucedido y de acabar pidiendo perdón a las víctimas. Ciertamente no en todos los casos. Las prisiones reflejan, como no podía ser menos, la composición de la sociedad, y en ella conviven rufianes y santos, pero, sobre todo, una inmensa mayoría para la que el diálogo, la responsabilización, el perdón, la reparación del daño y la reconciliación son valores relevantes. Mostrar la verdad de lo sucedido y mostrar-se con todos los sentimientos anejos resulta lamentablemente inviable en todo el proceso de instrucción, enjuiciamiento y ejecución penitenciaria. Con ello estamos privando al infractor y a la víctima de una dimensión fundamental netamente sanante: la empatía.

Hemos tenido el privilegio de recabar todas sus confidencias y sistematizarlas, este estudio constituye una nueva forma de verificar empíricamente nuestra más fuerte y arraigada convicción: merece la pena seguir apostando por los seres humanos, por la perfectibilidad que adorna su dignidad y por la orientación efectiva —no sólo retórica一 de las penas privativas de libertad hacia la reinserción social de los infractores.

Ojalá los datos que aportamos sirvan para humanizar el sistema penal y penitenciario y para dar un empujón definitivo para implantar las instituciones de la Justicia restaurativa —especialmente de la mediación- de manera que el sentimiento de empatía se traduzca simultáneamente en una efectiva minimización del daño causado a las víctimas de los delitos y en un paso adelante en la normalización vital de los infractores. Avanzar en esa dirección, más dialógica que dialéctica, dignificando a todos los actores del cruel sistema penal es el objetivo último de todos nuestros afanes, también de este.

\section{Los presos y la empatía}

La primera cuestión que planteamos busca conocer los sentimientos que la persona condenada tiene respecto de la víctima del delito, en caso de haberlo cometido. Obtuvimos 836 contestaciones. 


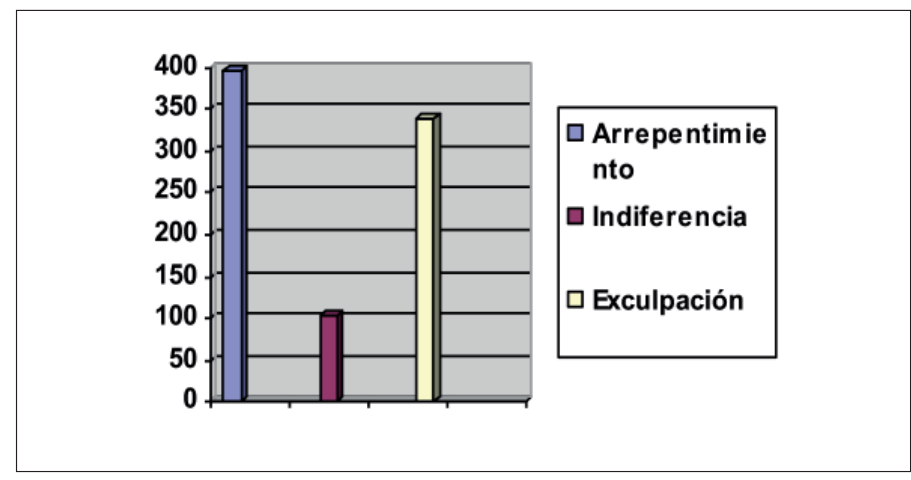

Fuente: elaboración propia

El 46\% de las personas que han contestado sienten malestar o pesar por el delito cometido y cercanía a la víctima en diferentes formas: arrepentimiento, culpabilidad, pena, vergüenza, auto reproche moral, dolor, necesidad de pedir perdón, empatía, respeto, amor (en la mayoría de estos supuestos se sobreentiende la existencia de una relación afectiva previa con la víctima).

El porcentaje de exculpación es también elevado: 40\%. Como veremos más adelante, este porcentaje se incrementa porque en determinados delitos, como, por ejemplo, los delitos contra la salud pública, el condenado no reconoce víctima concreta. Esta cuestión merece una reflexión que oportunamente se hará. Asimismo, la exculpación incluye otros argumentos: el mal funcionamiento del sistema penal, el titular del bien dañado, el consumo de drogas, la consideración de ser el condenado la víctima, la inocencia, el reproche al comportamiento de la víctima.

Por último, el sentimiento de indiferencia, 12\%, supone un pequeño porcentaje, pero significativo. Existen personas condenadas que no tienen ningún sentimiento hacia la víctima, a quienes el daño cometido les es indiferente o que, simplemente, carecen de opinión.

\subsection{Sentimientos de malestar o pesar por el delito cometido y cercanía a la víctima}

Los sentimientos de malestar o pesar expresados tienen una amplia gama de manifestaciones. Todos ellos permiten conocer que las personas condenadas son capaces de ponerse en algún momento de la condena en el lugar de sus víctimas. Pero, posiblemente, sea ya tarde. El daño está causado y no existe mecanismo legal que permita una sana expresión de la emoción; expresión que podría «sanar» una parte del dolor de la víctima, y aligerar la «carga» emocional del acusado en orden a su reeducación. 
La vida en prisión se hace difícil, no sólo por las exigencias del contexto de la vida carcelaria: pérdida de libertad, de intimidad, de espacio, convivencia obligada, manifestación continua de violencia física y/o emocional sino también por algo más complejo y dañino: la propia conciencia que, en estos casos, se llena de emociones de culpa, terriblemente pesadas de sobrellevar y afrontar. En la cárcel no existen instancias, o profesionales que permitan y coadyuven a la expresión y elaboración liberadora de tales emociones; ni siquiera puede hacerse entre presos, pues, en general, quien así lo haga, pone de manifiesto un margen de vulnerabilidad que en ocasiones se opone al necesario mantenimiento de la propia identidad de supervivencia carcelaria. Este trabajo ha sido un importante vehículo de expresión de tales sentimientos.

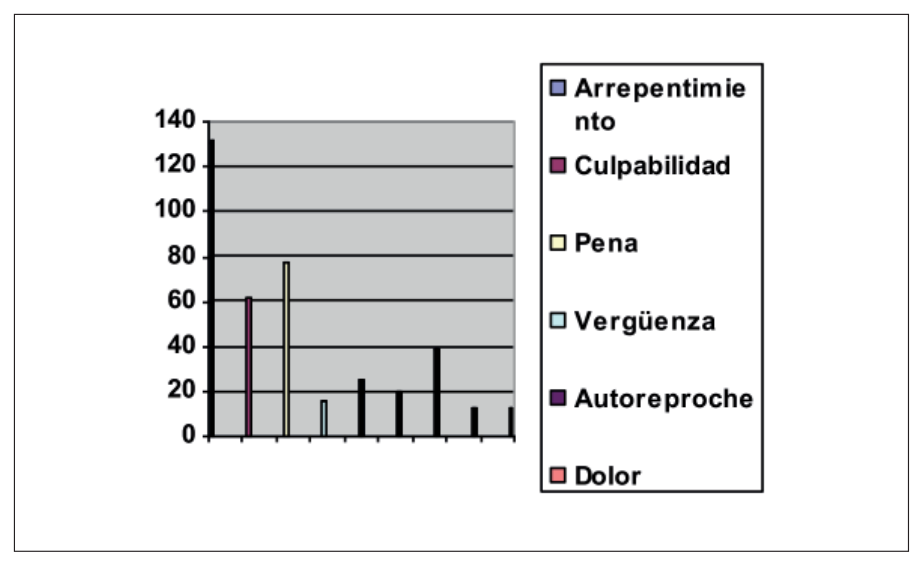

Fuente: elaboración propia

Las formas en que se manifiestan estos sentimientos de malestar o pesar son las siguientes:

1. Empatía. En total hay 13 personas $(3,5 \%)$ que muestran expresamente este sentimiento. Este porcentaje se amplía, obviamente a todos quienes manifiestan algunos de los sentimientos recogidos en algunos de los epígrafes siguientes. Hemos considerado como empatía aquellos sentimientos que revelan la capacidad de colocarse mentalmente en lugar de la víctima: (374) me pongo en su lugar; (1127) que me lo tendrían que haber hecho a mi. (895) ahora me doy cuenta del daño que uno hace. Otros captan la existencia de un derecho vulnerado (1314) pues creo que tienen todo derecho a sentirse atropellados y a pedir responsabilidades; o del miedo sufrido durante la agresión: (1045) el miedo que pasan los demás; (66) siento el susto que se debió llevar. Hay quien no puede escapar a la conciencia del dolor causado a su víctima y plantea formas de intentar reparar el daño: (417) jamás me paré a pensar 
en el dolor tan grande que le podia causar a mi víctima, pero estoy dispuesto a hacer trabajos comunitarios.

Por otra parte, cuando los delitos no tienen víctimas concretas, rostros determinados, los condenados, por lo general, no son capaces de ver el daño causado, salvo algunos que se hacen conscientes de ello al ingresar en la cárcel y tener que compartir la vida con otros internos que muestran «a voces» las secuelas físicas y mentales sufridas a consecuencia de la adicción a las drogas, o bien al pensar en sus propios hijos: (764) la victima mia es la sociedad. no lo volveria a hacer ya que tengo un hijo y no me gustaria que cayera en la droga; (1017) estoy por salud pública y soy conciente de la maldición que trae consigo la droga; (1144) he vivido de cerca el daño que causa la droga en la sociedad; (1410) yo era narcotraficante y ahora el ver a mi hijo, me ha hecho pensar todo el daño que he podido hacer a muchas familias. jlo siento mucho!; (26) cuando se trafica las víctimas son muchos empezando por uno mismo, lo unico que le queda a uno llegado este punto es aprender a tratar de dejarlo. la forma de repararlo es no volver a lo mismo y en la medida de lo posible, transmitir la experiencia propia a otras personas para que no caigan en los mismos errores, solo así se pagaría el daño que puedes haber producido a la sociedad - propósito de enmienda con deseos de ejemplaridad a los demás-. No falta quien muestra ante lo inevitable un deseo de paz: (635) espero que descanse en paz.

2. Vergüenza. Han contestado 16 personas (4\%) con ese sentimiento. Con o sin pena, pero consecuencia de la empatía, puede aparecer el rubor, la vergüenza por el daño causado: (151) siento vergüenza; (1607) siento verguenza, y lastima, le pido perdón, le deseo que prospere y se olvide de mi, porque yo he pecado. pero ante dios el que guarda rencor tambien es pecador. no quiero que con el daño que he hecho después sea pecadora ante dios, perdon. si hubiese algo que hacer?, digo la verdad. husted y yo sabemos que no he mentido.

3. Pena. Setenta y siete personas (20\%), como consecuencia de ponerse en lugar de la víctima, sienten una emoción de profunda tristeza y pesar por el daño causado: (15) pues meda mucha pena averle robado; (64) de pena y berguenza acia ella; (167) me da mucha tristeza por la familia. hi niños sufrir me siento como uno de ellos y por eso le pido ha dios que nunca suceda nada.

La pena es una emoción tan profunda que se puede llegar a pensar que no hay forma de suprimirla, aunque en la superficie se intente simular: (182) como antes no quiere habla porque fue un caso que pocas veces se ve. y no sigo hablando de esto porque tengo una pena que eso no me lo quitara nadie aunque yo lo esconda como si nada; u ocultar para evitarse el propio daño (909) no 
tengo mucho sentimiento ya que aqui las anulo para no hacerme daño sicologicamente ami aunque siempre se refleja al guno como pobre hombre o mujer como estara.

La pena aflora y permanece cuando el daño no puede ser reparado. Quizás por ello la reparación pueda ser un sano mecanismo de compensación de la pena: (22) pena por que no le pueda deborber lorrobado; (181) no creo que el susto que se llevara se le quitara pero me siento culpable por lo que hice y lo estoy pagando, me siento mal por lo ocurrido y me dio pena ojala pudiera reparar el daño que hice me ciento mal por ello.

4. Dolor: Han contestado 20 personas (5\%). Cuando la pena se intensifica se hace insoportable apareciendo, entonces, el dolor como manifestación más grave del autorreproche por el daño causado. Por ello necesita compensarse de alguna forma con justificaciones: (69) conprensión y dolor por ber el sufrimiento de esa persona me siento mal y yo no e matado nunca ni e apuñalado pero siento que no ubo otra salida nadie me educo yo con 8 años me fuy de casa de mi madre adoptiva y primava la supervivencia;(1212) mis sentimientos son de dolor por todo el daño que cometi a causa de una puta adicción (758). El dolor se incrementa cuando podría haberse evitado

5. Culpabilidad. Este sentimiento aparece en 62 personas de la muestra (16\%). La culpa es el sentimiento de autocondena que surge cuando pensamos que la conducta ha causado un daño: (834) culpa pena angustia por averles ruvado. Este sentimiento mantiene la mente aprisionada y encadenada a la servidumbre de la autopunición y de la depresión; es la fuerza de la gravedad que mantiene al ser humano clavado al dolor y que difícilmente se puede superar con el reproche porque el pasado ya no puede cambiarse: (165) remordimientos, culpabilidad e impotencia por no poder cambiar lo sucedido; (1004) remordimientos, ya que se cometio un crimen con una pistola que yo preste a un amigo, y no se si de no haberla dejado, los acontecimientos hubieran sido iguales. Para liberar la culpa, como veremos en el siguiente epígrafe, se hace necesario el perdón: (9) sentimientos de culpabilidad y esperando el perdon del daño ocasionado. Pero para ello se necesita un encuentro con la otra persona que viene dificultado por la vergüenza de enfrentarse al rostro del dañado: (48) de total culpabilidad por mi parte. si me las encontrase no podria mirarles a la cara por vergüenza.

La culpa genera dolor: (1385) el que le he destrozado y macado, asi como condicionado para toda su vida, como he hecho con su familia, con mi familia y conmigo... demasiadas personas destrozadas, marcadas, arrolladas, condicionadas, condenadas, 
arruinadas... etc... por mi culpa; y para poder sobrellevarlo necesita, cuanto menos una autoexplicación de la conducta.

A pesar de la inexistencia de víctimas concretas en los delitos contra la salud pública hay personas en quienes además de la sensación de haber causado un daño, aparece la culpa: (45) mi problema fue tráfico de drogas. soy consciente de mi sensación de culpa. víctimas son los consumidores; (1022) de culpa, pues jamás querria que mi hijo fuera toxicomano. y tal vez contribui con esto a probar la droga a muchos jovenes. pero la droga fue incautada, no salio al comercio de igual forma me siento culpable.

6. Arrepentimiento. Son 131 las personas que muestran este sentimiento (33'4\%): (7) que me arrepiento de lo hise; (91) estoy muy arrepentido de todo. Quien siente arrepentimiento por el daño causado parte de una situación previa de empatía, culpa, pena, y, por tanto, puede llegar a compartir el dolor sentido por la víctima. Este sentimiento resulta difícil de sobrellevar y más en la cárcel; por ello, quien lo siente necesita, al igual que con la culpa, expresar una justificación o al menos ofrecer una explicación de su conducta: (41) que no esta bien fue por causa de la droga, (191) pues esta claro que no se puede ir por la vida robando a las personas que ganan su dinero. aunque en mi caso lo hacia para las drogas; (1467) nunca he hecho daño fisico me gustaria explicarles a mis victimas que en esos momentos la droga era la causante de que yo necesitara dinero rapido. decepcion arrepentimiento.

El arrepentimiento está vinculado directamente a la culpa; esta mantiene a la persona unida a su pasado violento, incluso durante toda la vida porque lo ocurrido ya no tiene "marcha atrás»: (1061) le quité la vida a una persona y a pesar de escribirle a su familia pidiéndoles perdón y haciéndome cargo de la indemnización no hay dia que los remordimientos me invadan; (107) me he confesado, arrepentido y ojala pudiera cambiar las cosas. pero no puedo, lastre que llevo en mi vida, (465) el daño que he cometido no se puede reparar estoy por homicidio y es algo que no he podido superar aun porque era mi novia y no entiendo porque lo he hecho pero eso es algo con lo que vivo todos los dias sentimiento de culpa por lo que hize, de dolor causado a muchas personas, el sentimiento de arrepentimiento, mi vida a cambiado despues de todo esto, ahora tengo muchos enemigos y ningun amigo ypor ultimo el dolor de creer que haiga sido capaz de hacerlo;

Para la superación de la emoción sentida, las personas necesitan pedir perdón y reparar el daño. La primera premisa es difícil de realizar, pues el sistema penal no presenta oportunidades reales para ofrecer un contexto que permita que esa petición sea creíble y pueda manifestarse con toda la intensidad que requiere: (184) no he tenido oportunidad de intentar reparalo. ni de pedir perdon. 
son buena gente y quisiera pedirles perdon y demostrarles que he cambiado y que me arrepiento de el daño que les he causado. "no puedo juzgarlos»;(501) que lo siento muchisimo ya que debe aberlo pasado muy mal y me gustaria verle para pedirle mil veces perdon. Respecto de la reparación, esta puede ser económica, pero en ocasiones no la consideran suficiente para liberarse de la culpa.

A veces, la manifestación del arrepentimiento por unos hechos deja en evidencia la inocencia de otras acusaciones: (53) de arrepentimiento en las causas que he cometido. De las que no he cometido se me imputan dos violaciones juro a dios que soy inocente, (712) fui condenado por un delito que no cometi siento mucho lo que le paso a la victima, pero yo solo me limite a defenderme.

7. Necesidad de pedir perdón. Son 39 personas de la muestra las que expresan este sentimiento (9,2\%). La empatía, la culpa, el arrepentimiento, casi como una cadena lógica de consecuencias llevan a la necesidad de pedir perdón. El perdón es el puente que cruzamos para liberarnos de la culpa y del miedo: (661) que le he quitado algo que me hace sentir muy mal y desearía que por lo menos me perdonara; (37) me gustaria pedirle perdon y decirle que antes no pensaba las cosas que me acia pero aora si que las pienso.

En ocasiones el perdón requiere ir acompañado de un encuentro y una explicación: (183) me gustaría pedirlas perdon cara a cara y explicarles el porque lo hice; (562) que es buena persona, y todo fue una noche de cables cruzados por mi parte, sin pensar en las consecuencias, espero que me perdone, pues es vecino; (832) pediria perdon y desearia esplicarle personalmente las razones que llebaron a cometer el delito sobre su persona.las drogas, la falta de apoyo social, ectra. y que el objetivo siempre fue el económico y no personal. Y hay quienes transforman la petición de perdón, directamente, en reparación material: (1371) no procede lo que hice. me pesa mucho. no queria hacerle daño a la persona. no cabe en la cabeza de nadie prenderle fuego a la casa. me gustaria arreglarla y trabajar para ponerla a punto.

Cuando existe una relación previa en la que existe amor, la cuestión se complica, pues la culpa se desborda y la necesidad de sentirse perdonado es mucho mayor: (24) que la quiero y ante todo le pido perdon y no se de que forma compensar el daño que hice;(748) que la quiero mucho y espero que me perdone un día.

8. Auto-reproche moral. 25 personas han contestado con esta emoción $(6,3 \%)$. Con todo, a pesar de que aparezca o no la culpa, el remordimiento, el arrepentimiento, la pena, lo que sí aparece con claridad es el reproche moral de la conducta realizada: (79) que no esta bien; (1033) nunca devi apropiarme de lo que no hera mio. Es el primer estadio de la conciencia de la conducta dañina; indudablemente, 
quienes manifiestan culpa y arrepentimiento se hacen conscientes de la inmoralidad de su conducta, pero con mayor interpelación emocional hacia sí mismo por el daño causado. Con alguna superficialidad, se descarta la virtualidad terapéutica de la vivencia religiosa, a veces muy sincera y honda, de algunos internos.

9. Respeto y amor. Nueve personas de la muestra manifiestan la expresión "respeto» $(2,2 \%)$. En estos casos no existe manifestación de autoreproche moral, ni de sentimientos de culpa y similares, pero al menos hacer reflejar el «respeto» - 9 personas de la muestra-: (627) con mucho respeto; (1180) el sentimiento que tengo que la respeto mucho, dios, es la madre de mis hijos; (1183) le deseo todo lo mejor; (1210) que dios los coja y lo guarde de cualquier cosa mala; (1491) no opino que dios lo bendiga.

5.2. Ausencia de sentimientos, indiferencia por el delito cometido y hacia la víctima, necesidad de olvidar o simplemente falta de opinión

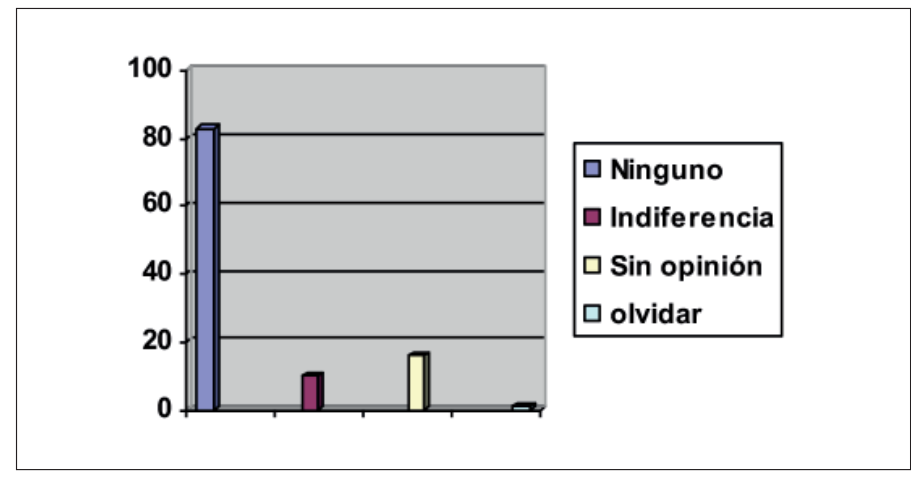

Fuente: elaboración propia

Únicamente el $12 \%$ de las personas (103) carecen de sentimientos respecto de la víctima o se muestran indiferentes por el daño causado. Hemos distinguido entre quienes no tienen pesar, ni exculpan o justifican su conducta en tres apartados:

1. Ningún sentimiento de autoreproche. La inexistencia de sentimientos frente a la persona agredida puede tener varias causas - existen 82 personas, el 10\%-. Hay quienes ni siquiera son capaces de dar explicación a la carencia de los mismos: (6) ninguno; (55) no tengo ningún sentimiento. Otros simplemente asumen que pudieron causar un pequeño susto, pero esto no les hace sentir ningún 
reproche propio: (70) pues ninguno malo, en todo caso, creo que se llevo un buen susto y si me pongo en su lugar creo que querría justicia despues de haverlo atracado. Hay también quienes justifican su conducta en la necesidad de obtener dinero y una vez en la cárcel ni siquiera han vuelto a plantearse si la víctima sufrió o no: (144) me es indiferente. en ese momento necesitaba el dinero para las dosis y no pensaba en mas. ahora ni siquiera me planteo que siento.

2. Indiferencia. Hay quienes manifiestan un sentimiento de indiferencia o despreocupación hacia la víctima (10 personas, 1,1\%): (47) no me preocupa demasiado; (254) las victimas guardia civil. un sentimiento de indiferencia y de impotencia. yo delinquí contra ellos y estoy pagando. ellos también delinquieron contra mi y no estan pagando; (308) que haga su vida y le vaya bien; (697) que se les quedaria cara de tontos.

3. Sin opinión. Hay otros que no tienen opinión sobre la cuestión que se les plantea1(0 personas, 1,1\%): (51) no opino nada por estar bajo los efectos de las drogas; (130) no lo se porque yo no estoy acustanbrado hacer delitos. Una persona necesita olvidar: (83) me gustaría olvidarme de la víctima (cumplo dos condenas por violencia de género y desobediencia judicial).

5.3. Mecanismos exculpatorios o de derivación de responsabilidad: jla víctima soy yo!, exculpaciones genéricas o proclamas de inocencia (reales o ficticias), exculpaciones por causa de la droga o por el mal funcionamiento del sistema penal, incluso haciendo responsable a la propia víctima; o simplemente lo sienten por las consecuencias sobre su propia familia

El 40,4 \% de personas acuden a este tipo de exculpaciones de su conducta cuando se les pregunta por los sentimientos hacia la víctima. Con estas respuestas podemos establecer las siguientes categorías de situaciones:

1. Derivación de responsabilidad al funcionamiento del sistema penal (3 personas, 0,8\%). Cuando, según la apreciación de la persona condenada, el sistema penal funciona erróneamente, los sentimientos por el daño causado desaparecen porque se camuflan bajo el daño sufrido por el sistema: (19) que se a pasado conmigo por manipulacion de la policia era un urto y me lo han metido con violencia y lo que estan haciendo conmigo es una injusticia de verdad lo que estan haciendo conmigo no es asi porque esto hai que pasarlo; 


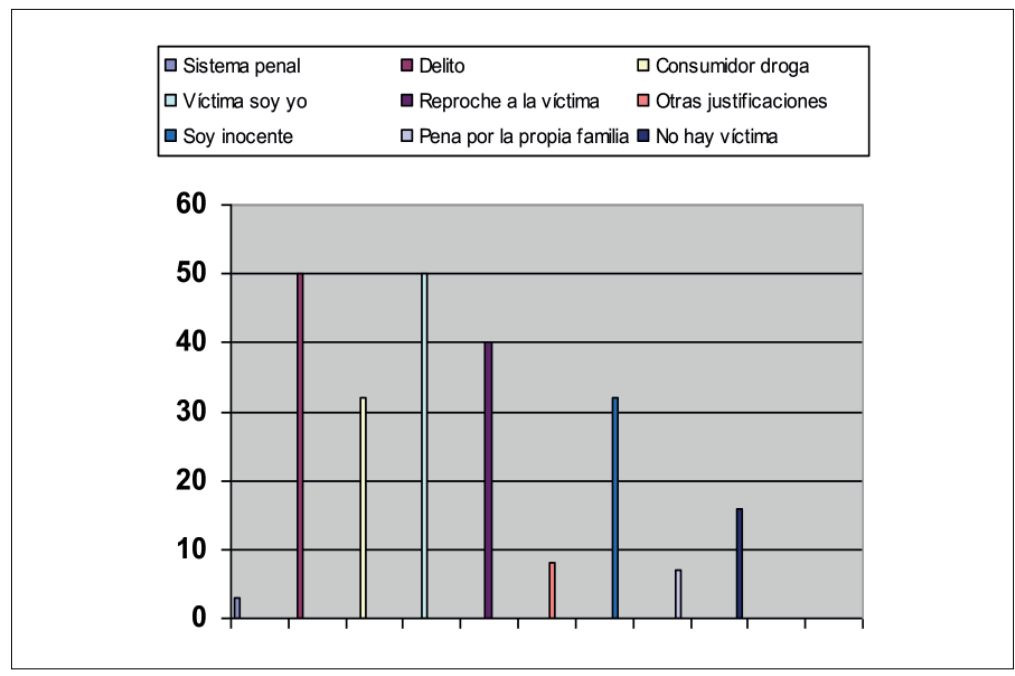

Fuente: elaboración propia

2. Irresponsabilidad por el tipo de daño causado o por la naturaleza o condición de la víctima (50 personas, el 14\%). Hay personas que manifiestan su irresponsabilidad en consideración a la condición empresarial o institucional del sujeto pasivo o víctima del delito: (86) las víctimas de mis delitos han sido casi todas empresas y la mayoría han sido estafadas con muy poco daño seguramente la milésima parte de lo que ellas defraudan; (549) las victimas son multinacionas se no hay victimas.

Otras veces la autoexculpación o minoración de responsabilidad tiene su fundamento en la causación de daños materiales sin afectar a la propia persona de la víctima o por la mera reparación por parte de un tercero del daño causado: (315) delitos menores, daños solo materiales; (1251) hay victima entre comilla yo robe en una tienda y si a ello le llaman victima pues lo siento por el pero no le hecho nunca daño a nadie solo me he llevado el \$.

3. Derivación de la responsabilidad al consumo de drogas (32 personas, 9,4\%). Las personas con adicción a las drogas exculpan su responsabilidad por el delito cometido en el hecho mismo de la adicción al tener que sufragarse el consumo como si se tratara de dos personas, de las que una de ellas fuera capaz de realizar actos que sin la adicción serían inconcebibles por la otra: (338) que lo hice por la droga sino llo nunca hubiera robado; (273) estoy por robar absurdo fruto de las drogas y las malas compañias, pero llevo una vida delictiva amplia que no creo que pueda subsanar nunca. los robos por los que estoy condenado si pues son autenticas tonterias en las que la mayor de las veces no tenia nada que ver. 
A pesar de ello, ya con distancia de los hechos, algunos son capaces de ponerse en lugar de la víctima y llegar a comprenderla.

4. La víctima soy yo. Cincuenta personas $\left(14^{\prime} 7 \%\right)$ se sienten víctimas de la situación, por lo que expresan su exculpación frente a la víctima judicial: (31) por me la victima soy «yo»; (61) estoy preso por robo con intimidación a entidad bancaria, y no experimento sentimiento de culpabilidad alguno, puesto que no me considero autor del mismo; (68): pues más que la víctima, pues victima fui yo por la amputación de mi pierna.

Algunas personas condenadas se sienten víctimas del funcionamiento del sistema penal y, desde esta posición, justifican su conducta, lo que les impide ponerse en el lugar de la víctima del delito: (129) en mi caso la victima fui yo mi error fue confiar en las justicia, por que yo me presente voluntariamente y ya llevo 9 meses sin saber nada de mi caso; (307) no hay victima en mi caso, la victima soy yo, estoy sintiendo las lagunas del amparo legar y el estado policial en el que vivimos, las pruebas acusan pero cuando no hay como mi caso es la mentira de la guardia civil.

Otros se sienten víctimas del propio sistema social: (187) no he hecho nunca daño físico a nadie, y los robos con intimidación sin dolo; creo que solo sufrirían el susto del momento. y según la conciencia que sigue hoy el mundo hay muchas víctimas que los culpables me parece duermen demasiado tranquilos. yo soy otra víctima.

5. Derivación de la responsabilidad al comportamiento de la víctima. Cuarenta personas $(11,8 \%)$ justifican la imposibilidad de ponerse emocionalmente en la situación de la víctima por la participación de ésta en los hechos: (210) el problema fue por dinero yo sólo le pege porque quería que me pagara mi dinero y como el sabía que yo tenía problemas con la justicia fue y me denunció como que yo le robé. y bueno dos años de condena; (314) estoy pagando / condenada por culpa de otros.

Uno de los principales reproches dirigidos a la víctima por su participación en los hechos consiste en haber relatado situaciones supuestamente falsas: (125) es falsa y embustera; (1168) fué una falsa; (145) no quiero hablar de ella, es una mentirosa; (1295) es la causante de mi desgracia, ya que ante amigos comunes, ha manifestado mi inocencia; (1404).

Por último, hay un grupo de personas que muestran un total desprecio por la víctima, bien amparándose en lo inevitable del sufrimiento humano: (235) Que se joda, a todos nos pasa algo en la vida, justo o injusto; bien en el sufrimiento propio. 
6. Soy inocente. (32 personas, 9,4\%). En este apartado aparecen personas que posiblemente sean realmente inocentes, total o parcialmente, de los hechos por los que cumplen condena: (1027) no tengo culpa ninguna ni he cometido ningun delito gracias a dios; (784) sentimiento ninguno por que no cometi ninguno; (1056) ninguno porque sabe que yo no lo asalte, todo la policia lo a manipulado.

7. Pena por la familia propia. Siete personas $(0,8 \%)$ únicamente se ponen en lugar de su familia a la que consideran víctima de su propia acción delictiva y de la desatención que, como consecuencia de aquella, ellos mismos han provocado: (504) en mi opinión toda mi familia es victima de mi herror porque ha sufrido mucho sobre todo mi esposa que la dejé con dos niños rodeados de miles de problemas; (676) en el momento que he cometido delito lo unico en que pienso es en mi familia nunca he cometido con daños a personas fisicas.

8. Delito sin víctima. 116 personas (34\%), casi todas ellas condenadas por delitos contra la salud pública, entienden que su acción delictiva no tiene víctima. Como ya hemos puesto de manifiesto en otro apartado, solo algunos de ellos han sido capaces de concretar y personalizar el daño cuando han pensado en sus hijos o han sentido en prisión cómo una gran parte de personas se encuentran presos por el consumo de drogas,: (20) no hay victima; (60) no existe ninguna victima. estoy aqui por un delito contra la salud publica asi que teoricamente no se ha hecho ningun daño a nadie en particular.

9. Exculpación genérica. Ocho personas (2,3\%) apelan a varias motivaciones para amparar su conducta delictiva; así: (153) como estas cosas que pasan no me gusta ni ver; (226) no tengo delitos de sangre no me resulto, jamás disfrute ni me resulto agradable tener que apuntar con un arma de fuego apersonas que no han hecho nada pero por circunstancias de la vida te vez metido en esta sucia vida y muy a pesar tuyo tienes que hacerlo.

\section{La empatía de los presos enfrentados cara a cara con la víctima}

Preguntamos también a las personas condenadas qué dirían a la víctima si la tuvieran delante. La situación es distinta a la anterior; ahora se trata de que la persona condenada reflexione teniendo ante sí el rostro de la víctima. El encuentro con ella ¿cambia la percepción del daño? ¿modifica el sentimiento hacia ella? 


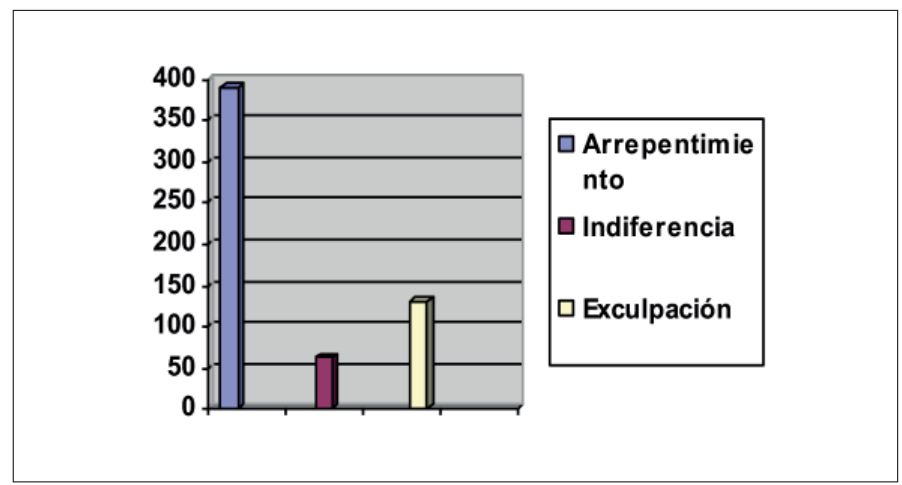

Fuente: elaboración propia

Es significativo que cuando en esta pregunta ponemos a las personas condenadas «virtualmente» ante la persona a quien han agredido para que expresen lo que deseen, los porcentajes de sentimientos de pesar o arrepentimiento hacia la víctima se mantienen similares $(46 \%)$ a los expresados sin tenerla delante, pero los de indiferencia disminuyen del $12,5 \%$ hasta el 7,5\%, y los de exculpación, desde el $40 \%$ al 15,5\%. Parece como si el encuentro con la víctima de las personas que sienten pesar o arrepentimiento les permitiera expresar el sentimiento: dolor, perdón o disculpas, reparar o dar explicación. Pero, por otro lado, enfrentarse al rostro del lesionado supone una confrontación consigo mismos permitiéndoles caer en la cuenta de la importancia del daño causado, porque ya no hay lugar para la exculpación. No se incrementa el arrepentimiento, pero desaparece la exculpación de la conducta. Aparece el silencio responsabilizador.

\subsection{Sentimientos de pesar o arrepentimiento por el delito cometido y cercanía a la víctima}

El porcentaje más elevado de las respuestas da muestras evidentes de pesar o arrepentimiento por el delito cometido. Estas personas coinciden con aquellas que tenían tales sentimientos. Lo hacen de varias formas: pidiendo perdón, intentando dar explicación de lo ocurrido, pidiendo disculpas o intentando reparar y mostrando cariño y apoyo.

1. Perdón: Es una necesidad que quisieran poder expresar 336 personas $(85,9 \%)$ de todas las que contestan a esta pregunta. La necesidad de sentirse perdonado se hace imperiosa: (498) por favor perdonarme; (1193) perdón y perdón solo le pido a dios; (1226) amigo, perdoname por todo el daño que te ocasione, te pido porfavor que me perdones y que mis disculpas y mi perdon te lo pido como un ser humano que soy, somos y seremos siempre. 


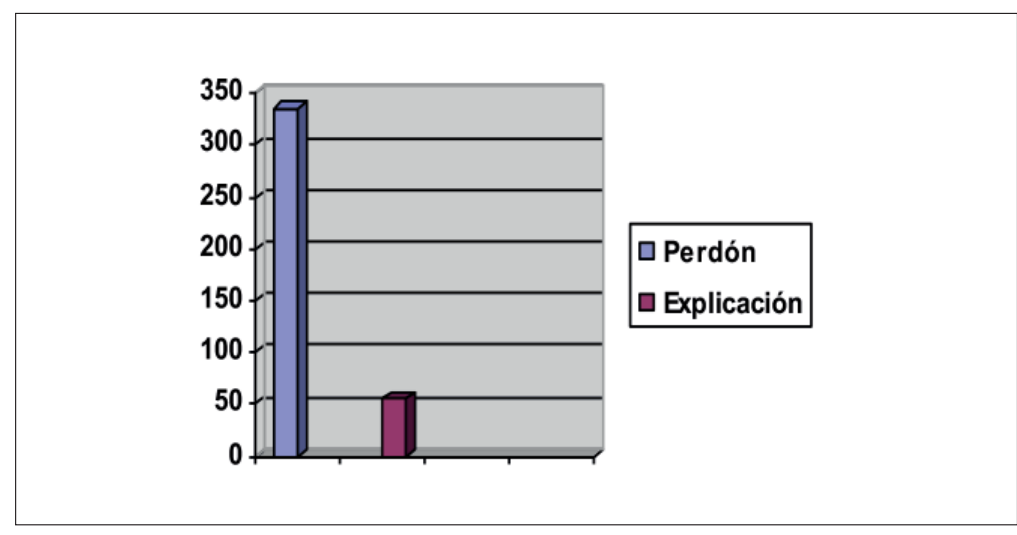

Fuente: elaboración propia

El perdón, en todo caso, requiere un proceso que viene de la mano de la necesidad de un diálogo previo, en ocasiones con apoyo terapéutico: (1024) no sabria como hacerlo de la forma adecuada pero pediria ayuda de un psicologo para que me acompañase.

2. Dar explicación: El encuentro con la víctima permite al condenado dar una explicación de lo ocurrido. 55 personas $(14,5 \%)$ lo necesitan. Este dato es importante, porque manifiesta la forma en que la víctima puede conocer la motivación de la conducta de su agresor, llegar a comprenderla o ver su propia participación en el conflicto, y así poder obtener la tranquilidad que da el conocimiento, la comprensión y la verdad.

También hay quien necesita expresar emociones: (270) que la quiero, que me estoy reabilitando que me perdone, que sueño todos los dias con el cariño que me daba; (1120) me gustaria vivir con tigo y hacerte feliz para siempre; (1579) que siempre tendra un hueco en mi corazón.

6.2. Ausencia de sentimientos, indiferencia por el delito cometido y hacia la víctima, necesidad de olvidar, consideración de falta de víctima o simplemente carencia de opinión

1. No sienten nada 63 personas $(10,7 \%)$. Hay quienes no pueden expresar nada: (6). Unos, porque les es materialmente imposible: (52) nada no la puedo encontrar; (1048) ipor desgracia no vive! 


\section{Conclusiones}

1. El estudio contradice la percepción generalizada de la persona privada de libertad como ser amoral, incapaz de ponerse en el lugar del otro, refractario a todo tipo de sentimiento.

2. «Las instituciones inhiben los sentimientos». Con la sustitución del diálogo por el interrogatorio cuasi-inquisitorial, se ha privado al proceso del valor de la palabra; de la posibilidad de incorporar algo más que datos y razones. Nos hemos quedado sin explicaciones y sin lugar para los sentimientos. Muchas veces la víctima lo que quiere es un porqué y la garantía de que no se volverá a repetir el daño en el futuro.

3. Lamentablemente la actual configuración de la instrucción, el enjuiciamiento y la ejecución penitenciaria dejan muy poco espacio a la expresión de sentimientos y a las actitudes responsabilizadoras y reparadoras que conlleva. Nos parece importante hacer hincapié en que uno de los objetivos de cambio supone implicar a las personas inmersas en un conflicto en regular las emociones y gestionarlas; se trata de permitir la canalización de dichas emociones para que el comportamiento futuro sea lo más adaptado posible, en la búsqueda de un objetivo más ideal como es favorecer la conciencia emocional, pues «no tener conciencia de las propias emociones nos deja a merced de las emociones incontroladas».

4. Es preciso dotar de mecanismos sociales de liberación de dicha culpa (arrepentimiento, reparación del daño, petición de perdón) que canalicen esta de forma positiva para el propio sistema social, permitiendo devolver a la norma su plena eficacia y restablecer la normalización emocional de los implicados. De ahí la urgencia de legislar e implementar, como en la actualidad está ocurriendo por las políticas de la actual Secretaría General de Instituciones Penitenciarias, de programas de Justicia restaurativa (mediación penal, diálogos y encuentros restaurativos, etc...).

5. La existencia de personas que no ponen de manifiesto ningún auto-reproche acerca de su comportamiento, además de validar la objetividad del estudio, debe suponer un reto a las Instituciones Penitenciarias para trabajar en cuanto minimice la violencia (la activación de mecanismos de defensa reactiva es un antídoto frente a la empatía) y genere actitudes de autorrespeto y responsabilización.

6. Sin duda alguna, el fomento de la empatía es un valor y tiene consecuencias positivas para todos (víctima, infractor y sociedad). Por consiguiente, desde esta novedosa clave deben revisarse no sólo las leyes sino también las malas prácticas policiales, judiciales y 
penitenciarias que pueden llegar a blindar esta dimensión tanto en los infractores como en sus víctimas y en la propia colectividad.

7. No podemos silenciar la necesidad de extremar la vigilancia para que se eviten los errores judiciales que acaban llevando a prisión a personas inocentes. Por pocos y difícilmente demostrables que sean los supuestos, existen, y constituyen una vigorosa llamada de atención frente a cualquier forma de populismo punitivo, abuso de la función simbólica del Derecho penal y uso excesivo de la cárcel como respuesta y una reivindicación de la importancia de no bajar los listones de las garantías procesales y la vigencia de los derechos fundamentales y de su contenido sustancial sin rebajas legales o jurisprudenciales.

8. El estudio revela la importancia de seguir apostando por la orientación reinsertadora de las penas y el cultivo de la escucha a las personas y la atención a sus necesidades como presupuesto de la responsabilización y reparación de los daños infligidos por el delito.

\section{Bibliografía}

Brennan, I., y KlaAsen, E. (dirs.), Building Bridges. Restorative Dialogues between Victims and Offenders. A Guide to Establishing and Running the Building Bridges Program, 2015, disponible en http://restorativejustice.eu/bb/wp-content/uploads/sites/3/2016/02/WS-2-D2.4-BuildingBridges-Guidebook-.pdf.

Cardenal Montraveta, S., «¿Eficacia preventiva general intimidatoria de la pena? Consecuencias para la decisión sobre la suspensión de su ejecución», Revista Electrónica de Ciencia Penal y Criminología (RECPC), $\mathrm{n}^{\circ} 17-18,2015$.

DiEZ RIPOLLÉs, J.L., «El nuevo modelo penal de la seguridad ciudadana», $R E C P C, \mathrm{n}^{\circ}$ 06-03, 2004.

Francés LecumberRi, P., y Santos Itoiz, E., «La mediación penal, ¿un modelo de justicia en el sistema de justicia penal?», Nuevo foro penal, vol. 6, n. 75, 2010, pp. 53-93.

Gallego Díaz, M.; Cabrera Cabrera, P.; Rios Martín, J. C.; Segovia BerNABÉ, J.L., Andar $1 \mathrm{~km}$ en línea recta: La cárcel del siglo XXI que vive el preso, Madrid, Universidad Pontificia Comillas, 2012.

GaVRIElides, T., Y ARtinopoulou, V., Reconstructing restorative justice philosophy, Farnham, Ashgate, 2013.

GUSTAFSON, D. L., «Exploring treatment and trauma recovery implications of facilitating victim-offender encounters in crimes of severe violence: lessons from the Canadian experience», en E. ElLIOTT y R.M. GoRDON 
(eds.), New Directions in Restorative Justice: Issues, Practice, Evaluation, Cullompton, UK, Willan Publishing, pp. 193-227.

KLosin, A., ET AL., "Transgenerational transmission of environmental information in C. elegans» Science, 21 abril 2017.

Manzanos Bilbao, C., Cárcel y marginación social, Bilbao, Gakoa, 1997.

Martínez Escamilla, M., «Justicia restaurativa, mediación y sistema penal: diferentes estrategias, ¿los mismos objetivos?», en VVAA, Estudios Penales en homenaje a Enrique Gimbernat, tomo I, Madrid, Edisofer, 2008.

Mir Puig, S., Derecho Penal. Parte General, Valencia, Tirant Lo Blanch, 2015.

Olalde Altarejos, A., 40 ideas para la práctica de la justicia restaurativa en la jurisdicción penal, Madrid, Dykinson, 2017.

Pascual Rodriguez, E. (coord.), Los ojos del otro, Santander, Salterrae, 2013.

Ríos Martín, J.C. y Cabrera Cabrera, P.J., Mil voces presas, Madrid, Universidad Pontifica Comillas, 1999.

Ríos Martín, J.C. y Cabrera Cabrera, P.J., Mirando el abismo: el régimen cerrado, Madrid, Universidad Pontifica Comillas, 2003.

Ríos Martin, J.C., Biografía de la reconciliación. Palabras y silencios parar sanar la memoria, $2^{\mathrm{a}}$ ed., Granada, Comares, 2020.

Rossner, M., Just Emotions. Rituals of Restorative Justice, Oxford, Oxford University Press, 2013.

Valverde Molina, J., La cárcel y sus consecuencias, Madrid, Edit. Popular, 2004.

VARona Martínez, G., La mediación reparadora como estrategia de control social, Granada, Comares, 1998.

\section{Prensa}

Saez Valcarcel, R., Entrevista. Revista Galde. Otoño 2016.

Vives Antón, T., «La injerencia, el error y el derecho», Diario El País, 1 de abril de 2010. 